\title{
Special topic
}

Janet G. Hering*

\section{Women as leaders in academic institutions: personal experience and narrative literature review}

https://doi.org/10.1515/pac-2018-0603

\begin{abstract}
For the last 12 years, I have had the pleasure and privilege to serve as the Director of the Swiss Federal Institute of Aquatic Science and Technology (Eawag) and as a professor at the Swiss Federal Institutes of Technology (ETH) Zurich and Lausanne (EPFL). My affiliations have afforded me a rare opportunity to observe the structure and governance of academic institutions and to reflect on my own experience in institutional leadership. I have attempted to place my experience in the context of the literature on leadership, particularly that relating to women and academia. On the basis of my experience and reading, I make some recommendations for women faculty, for women in positions of institutional leadership in academia, and for academic institutions. I am deeply convinced that greater participation by women (and members of other under-represented groups) in institutional leadership is needed if academia is to make a meaningful contribution to addressing the huge challenges that face humanity.
\end{abstract}

Keywords: academia; Distinguished Women in Chemistry and Chemical Engineering; diversity; gender; leadership.

\section{Introduction}

As a preface, I would like to point out that leadership in academia operates at multiple levels. This is a consequence of the "bottom-up", entrepreneurial model of research universities. Individual professors, especially those who lead large research groups and/or large externally-funded projects, exercise leadership and have substantial executive management responsibilities. These responsibilities overlap significantly with those of individuals in positions of institutional responsibility within academia. Here, I focus on institutional leadership, which I believe has aspects that transcend the contributions made at the professorial level. In this context, I would like to highlight three aspects of institutional leadership [1-4]. First, institutional leaders can and should cultivate a broad, strategic view of their organizations as well as the positioning of their own institutions with respect to its peers. Second, institutional leaders have considerable direct influence on their institutions, for example, in setting policies, in making decisions about hiring and promotion, in distributing internal resources, and in setting the tone and standard of behavior for the institution. Establishing good policies, decisions and working conditions can improve institutional productivity and competitiveness. And third, they represent the institution personally and can influence how the institution, its policies, and its activities are viewed externally. These latter aspects can generate a multiplier effect for the decisions and strategies of institutional leaders.

In particular, I am convinced that the advancement of women into positions of institutional leadership in academia is vital for the future of academic institutions. In 2000, Prof. Sheila Widnall (who served as

*Corresponding author: Janet G. Hering, Swiss Federal Institute of Aquatic Science and Technology (Eawag), Dübendorf, Switzerland; Swiss Federal Institute of Technology (ETH) Zürich, Zürich, Switzerland; and Swiss Federal Institute of Technology Lausanne (EPFL), Lausanne, Switzerland, Tel.: +41 58765 5001, E-mail: janet.hering@eawag.ch 
Secretary of the US Air Force under President Clinton) made a powerful statement about the importance of women's participation in engineering. I have taken the liberty of adapting this for academic institutions as follows: "If women don't belong in [academia], then [academia] is irrelevant to the needs of our society. If [academia] doesn't make welcome space for them and embrace them for their wonderful qualities, then [academia] will become marginalized as other [institutions] expand their turf to seek out and make a place for women" [5].

In this piece, I present my personal experience as the director of the Swiss Federal Institute of Aquatic Science and Technology (Eawag) in the context of selected literature on women in academic leadership. I do not, by any means, claim to provide a comprehensive review of this literature, but I hope to provide motivation for my readers to explore this scholarship and the issues of institutional leadership in greater detail.

\section{My personal experience}

In January 2007, I began my first term as Director of Eawag, an autonomous research institute with about 440 employees (360 FTE) and direct federal funding of almost 50 million Swiss Francs at that time [6]. Since then, Eawag has grown by about $14 \%$ in personnel and $20 \%$ in direct federal funding [7]. (Note that, since Eawag does not grant degrees or professorial titles, some laboratories of professors (with their doctoral students and other research staff) are housed at Eawag but are not reflected in our formal employment statistics).

I moved to Eawag from the California Institute of Technology (Caltech), where I was a professor in charge of my own research group. I had also held a position as Executive Officer (Caltech's equivalent of a Department Chair). Because of Caltech's small size and flat hierarchy, this position carried relatively little budget or management authority. Through this position, however, I had quite a bit of contact with the Chair of the Division of Engineering and Applied Sciences (EAS) and participated twice in faculty committees to recommend new Division Chairs (Caltech's equivalent of a Dean).

When I moved from Caltech to Eawag, I was well aware of the deficits in my experience in academic leadership and executive management. This motivated me to reflect on my (limited) past experience, to educate myself for the coming challenges and to pay attention to the various aspects of the role that I would take up when I moved to Switzerland.

\section{What I "knew" going in}

Despite my limited experience as an Executive Officer at Caltech, I could draw some conclusions from observing the Division Chair and the selection process for this position. First, it was clear that individual faculty members had widely varying expectations for the performance of individuals holding positions of institutional leadership in academia. (Note: for convenience, I will simply refer below to institutional leaders without specifying "in academia"). Second, I observed that the EAS Division Chair dedicated substantial time and effort to his role as Chair. From both of these observations, I drew the conclusion that institutional leadership is hard work that takes a lot of time. When I moved to Eawag, I had no expectation that I would have an easy job awaiting me.

I was also well aware that the demands on and expectations of institutional leaders are quite different from those on and of professors. The obvious corollary is that success in institutional leadership cannot be assumed based on success as a professor. Indeed, "very little of what is required to achieve tenure success as a faculty member translates to effective preparation for broader institutional leadership" [8]. That "scientists are essentially trained to be solo contributors" [3] does not ease this transition. 
From my own professorial experience, I knew that a "command and control" model of leadership would be ineffective simply due to lack of acceptance by faculty and senior scientists. I recognized that, although there might be some similarities between academic and corporate leadership, there would also be important differences $[3,9]$. This realization made me somewhat wary of conventional leadership training and of expectations that derived from non-academic experiences.

\section{How I prepared myself and started at Eawag}

Once I knew that I would be moving to Eawag, I immediately started working with a computer-based, German language tutorial. I also started reading a series of books on management and leadership, some relating specifically to academic or women's leadership and others being more general. I have continued this reading throughout my directorship. Some of these books are cited throughout the text; I have taken the liberty here to cite a few others that I found particularly insightful [10-16].

Of course, reading about leadership is a far cry from leading, and as soon as I started working at Eawag, I inevitably started making mistakes. Learning from my mistakes has been an important, though painful, part of my professional development. I have also sought advice and guidance from senior colleagues at Eawag and others knowledgeable about the institute and have benefited from consulting with and observing leaders at other academic and research institutions.

I was convinced that I could only be successful as Eawag's Director with the strong support of my senior colleagues, particularly the Deputy Director, Prof. Rik Eggen, the other four (now five) members of the Directorate and the Heads of the 12 Research Departments. Fortunately, these individuals (and indeed all the staff) were deeply loyal to Eawag as an institution. Also fortunately, they realized that the best way to ensure Eawag's success was to support me in my role as institutional leader. Again from my own professorial experience, I understood that the best way to gain such support would be to identify and promote initiatives that tracked the interests of Eawag's (senior) researchers and to place the interests of the institution ahead of my own position as an institutional leader. Perhaps ironically, I was aided in this by my poor command of German, which is the most widely-used of Switzerland's four national languages. Because of this and also because of my US citizenship, I encouraged other senior colleagues to represent Eawag to the media and in public. I also felt that, because I am not Swiss, it would not be appropriate to use my appointment as an example for women's accomplishments; I do hope that this missed opportunity has been offset by my subsequent success in my position.

\section{What I have learned}

I arrived at Eawag with a deep respect for the accomplishments of my scientific colleagues. From my own personal experience, I understood that "it is often via desire and motivation to do research that flourishing occurs" [17]. I came to appreciate that such strong intrinsic motivation was shared not only by Eawag's researchers but also by members of the technical and administrative staff. I also learned that such intrinsic motivation can be easily damaged by "bureaucratic systems [that] hinder creativity and systemic tools to measure worth [that] encourage competition, complicity and careless-ness" [17].

As the daughter of two lawyers, I came to my position with an appreciation of the value of good procedures and processes, which can save substantial time and effort. Requests that are covered by existing procedures and processes can be dealt with in a standardized way, saving time and energy to deal with non-standard requests that need to be treated as exceptions. For example, the Eawag Partnership Program (EPP) developed out of a single, ad hoc request (Box 1) and subsequently provided a standardized process for selecting EPP Fellows from low- and middle-income countries to visit Eawag. Good procedures and processes are also a valuable tool for internal communication, reducing the need to explain decisions. 
Box 1: The Eawag Partnership Program (EPP) for developing countries [18, 19].

The EPP began with a single request for a scholarship for a student from a low-income country to make a short visit to Eawag. In order to avoid handling such requests on a case-by-case basis, the EPP committee was established in 2008. One main component of the EPP are student fellowships for short visits to Eawag. Since 2008, 83 fellowships have been granted to students from 28 low- and middle-income countries. The EPP also took on the responsibility for administering Eawag's longstanding collaboration with IHE Delft (formerly UNESCO-IHE). Every year, three students from IHE-Delft conduct their Master's thesis work under the supervision of Eawag researchers.

As I had read in many management books, organizational culture is a central factor in determining the success of an organization. As I learned about Eawag's organizational culture, I came to appreciate its flat hierarchy and the flexibility and freedom that this affords its researchers. I also realized that this is both consistent with and shaped by the strong Swiss traditions of direct democracy and subsidiarity. I was able to benefit from the ability and willingness of my Eawag colleagues to accept responsibility and authority for important decisions. The EPP Committee, for example, takes full responsibility for EPP administration.

People respond to organizational culture but they also shape it. It is a widely-repeated truism that people are key and that hiring and promotion decisions are the most important decisions made within an organization. In my first years at Eawag, I realized that the information that tenure-track researchers were receiving was often inconsistent, depending on their home Research Department. As Director, my first formal contact with the tenure-track researchers (called the ${ }^{1 \text { st }}$ Career Discussion) came only after the first 1.5 years of employment (with the Directorate decision on the contract extension). To provide better orientation and support for our up-and-coming talent, I initiated, in 2011, $0^{\text {th }}$ Career Discussions with new tenure-track researchers, which take place after they have been at Eawag for only a few months. With these meetings, new tenure-track researchers receive uniform information about the tenure evaluation processes and the expectations of the institution. A summary of this information is now also available in the document Eawag's Research Environment [20].

I came to realize that many of the mistakes I made could be attributed to poorly-communicated expectations and unspoken assumptions. In retrospect, I could see that I should have asked more questions, even (or perhaps especially) in situations where I did not feel in need of guidance. I would have benefitted from a clearer sense of my colleagues' perceptions, which I recognized as having their own intrinsic validity regardless of whether or not they agreed with mine. I also increasingly recognized the importance of a culture of open discussion, which is not always easy to foster and maintain. Mutual respect among colleagues is a prerequisite to intellectual exchange in which ideas can be challenged and work can be improved [21, 22].

From the beginning of my tenure as Eawag's Director, diversity has been an important concern for me. In 2010, Eawag established an Equal Opportunity Committee, the EOC (Box 2). An early contribution of the EOC was to consult with the Directorate on procedures to recruit and retain women scientists.

Even following good procedures and processes, such as increasing the transparency and consistency of career discussions, cannot eliminate all difficult decisions. The hardest part of institutional leadership involves conflicts between the interests of the institution and those of individuals. In academic institutions, such conflicts most often arise in the context of the tenure evaluation process. Communicating negative tenure decisions is the least attractive part of my job, but it is necessary for the long-term success of the

Box 2: Eawag's Equal Opportunity Committee (EOC) [23].

The EOC was established as a sounding board for the Eawag Directorate on diversity policies. For example, in 2008, the Directorate, after consultation with the EOC, established guidelines for search committees on increasing diversity (Policy Directive 08-07). A key aspect of these guidelines is that milestones are set for diversity during the search process (e.g. regarding the diversity of the short list of candidates invited for interviews). In 2017, the Tailwind program to provide support for mothers returning from maternity leave was established (Policy Directive 17-03). These Eawag documents are available at the Open Science Framework project "Advancement of Women in Science \& Technology" (osf.io/rnjs4). The EOC has also conducted surveys and workshops on topics such as part-time employment. 
institution. I learned how difficult it can be to recover from a bad hiring decision, particularly for an upper management position. Investing in professional recruitment services is certainly worthwhile to avoid such situations.

\section{Rewards of leadership}

I have also come to appreciate the many rewards of institutional leadership in an academic research institute. I find it deeply rewarding to contribute to the success of talented individuals and to Eawag as an institution. Partly through the hiring, mentoring and promotion of our researchers, both women and men, I feel that I have been able to guide and shape Eawag. Since 2007, I have been involved in making hiring decisions for 45 tenured or tenure-track researchers; 15 of those hired onto the tenure track have already been promoted. I am gratified that many of these colleagues are very successful at Eawag and I hope that innovations (like the $0^{\text {th }}$ Career Discussion) have contributed to this success. During this period, five Research Department Heads and six Directorate members have also been appointed. I am proud that the representation of women in Eawag's tenure-track and tenured scientific staff is above $20 \%$ at all levels including the Heads of the Research Departments and is above $40 \%$ at the level of the Directorate.

Together with the other members of Eawag's Directorate, I am also able to guide the institution by allocating internal funds for research projects and programs. Although this internal funding is only about $10 \%$ of the funds that our researchers acquire from external sources, it allows us to promote Eawag's strategic goals, gain competitive advantages and strengthen the institutional capacity for inter- and transdisciplinary research. Examples of Eawag's internally-funded, strategic programs include EcoImpact, which examines the impacts of the upgrading of selected Swiss wastewater treatment plants to remove micropollutants [24]. Since the early 1990s, Eawag has supported the development of source separation technologies as an alternative to conventional wastewater treatment. Recent advances include the commercialization of technology for the conversion of urine to fertilizer by the Eawag spin-off VUNA Ltd. [25].

Measures and decisions relating to staffing and (internal) funding are powerful tools to demonstrate an institutional focus on the quality and impact of research rather than its quantity [26] and to support and value different approaches to research and scholarship [17]. I have found that Eawag researchers are strongly motivated by the outcomes and impacts of their research. I admire and share their willingness to give life to the famous words of US President Harry S Truman "It is amazing what you can accomplish if you do not care who gets the credit".

\section{Recommendations}

I would like to conclude with three sets of recommendations: for women faculty, for women in positions of institutional leadership in academia, and for academic institutions. These recommendations are based on my own experience and also on my reading of the literature on women in academic leadership.

\section{For women faculty}

Probably you are successful as a professor and enjoying your independence and the freedom to pursue your intellectual interests. Perhaps you are not thinking about moving into a position of institutional leadership. I would urge you not to discount this possibility, since it offers many rewards (as illustrated above). As women, we may not consider ourselves as likely candidates for leadership positions; we may subject ourselves to our own unconscious bias as to what attributes a leader should have [4, 8, 27]. My own first thoughts about the Eawag Directorship was that a foreign national would not be successful in this position. Fortunately, my misgivings turned out to be unjustified. Keep in mind that leadership skills can be learned and that allies can be cultivated. 
Box 3: The ETH Women Professors Forum (WPF).

The ETH WPF [29] was founded in 2012 by Prof. Ursula Keller as an outreach activity of the National Center of Competence in Research (NCCR) for Molecular Ultrafast Science and Technology (MUST). The WPF could be launched thanks to in-kind support from the NCCR MUST [30], the dedication of Prof. Keller as its founding President, and helpful advice and encouragement from the Yale Women Faculty Forum [31]. The ETH WPF offers networking opportunities for its members and provides recommendations for measures for the recruitment and retention of women faculty. The ETH WPF is dedicated to the goals of attracting girls and women to science, retaining women scientists, and promoting excellent individuals to the highest level of academia.

I would suggest that you take the opportunity to develop management and leadership skills; these will be useful however your career develops. Keep your options open. As Sheryl Sandberg wrote, "Don't leave before you leave" [28]. It may be that you find the leadership styles that you have observed (or been subjected to) unattractive. Take the opportunity to learn about alternative styles of leadership [1, 12, 16, 21].

Look for opportunities to gain experience. This may be as simple as observing or talking with institutional leaders, especially (but not only) women. You can meet women leaders in your institution by joining an association of women faculty, like the ETH Women Professors Forum (Box 3), or forming one if none exits. Perhaps you could take on a supporting or temporary role in institutional leadership. This would give you a basis for a more informed decision about future options.

When those future options arise (and they probably will), don't be afraid to take risks [26]. The process of applying for a position in institutional leadership can be a valuable learning experience even if your application is declined or you decide you don't want the position in the end. You will learn a lot about the institution and also about yourself. And if you take on the position, you will learn even more.

\section{For women in positions of academic, institutional leadership}

Congratulations and thank you for your service to academia! I hope that you take the time to appreciate your own hard work, success and contributions, as well as to thank others who have supported you and contributed to your success. I urge you to use your positions to help other women advance, which I am convinced will improve academic institutions. You are probably already mentoring female colleagues, but I urge you to consider taking on a more active role as a sponsor [32]. I encourage you to be willing to innovate within your own institutions and to implement innovations that have proved effective elsewhere (Box 2). I hope that we will all work collectively within and across institutional boundaries to support each other and benefit from our experiences. Associations of women faculty (Box 3) can be important tools for mutual support and collective action. I hope that we will be willing to identify and criticize "subtle form[s] of institutional discrimination expressed as normative institutional rules and practices" [8] and to work to mitigate unconscious bias [27]. I hope that we will all work to expand leadership opportunities for women, aiming for 30-35\% representation of women at all levels. This has been identified as the critical level of representation needed so that the participation of women is seen as normal rather than exceptional $[4,9]$. We should work with our institutions to make leadership positions attractive to women [33,34], expanding our expectations for institutional leadership to include collective and transformational leadership models [9, 35-37].

\section{For academic institutions}

Academic institutions should welcome and support women as leaders at all levels, providing better training and more support for both women and men as they move into positions of institutional leadership [38, 39]. The underrepresentation of women in leadership positions (especially institutional leadership) needs to be recognized as a problem for academic institutions that has varied but identifiable causes [9, 33, 40, 41]. Academic institutions are, of course, not the only institutions facing such issues [2] but the role of academia 
in training future leaders conveys a special responsibility [5]. It is particularly important that academic institutions provide role models of women in leadership for both their female and male students [5, 42]. Furthermore, academia should be cognizant of the negative message that is conveyed by training women as students but being unwilling or unable to retain their talent for institutional leadership.

Academic institutions need to be aware of and actively combat unconscious bias [27] and recognize the limitations of the "research-based prestige economy" [43]. "Changing the women" is not the answer [8, 35, 44]. Institutions need to ensure that women are not excluded or discouraged by poor governance and lack of transparency [45] or, even more egregiously, by gender or sexual harassment [46, 47]. Women in positions of institutional leadership should be encouraged to be innovative and try new models of leadership. Academic institutions should be willing to learn from the experience of women, especially those in leadership positions, and should actively support associations of women faculty (Box 3 ) as a valuable and important complement to equal opportunity and diversity offices.

Academic institutions will need to engage women (at all levels) in the critical task of adapting academia to meet the needs of society. Humanity is facing huge challenges - diverse perspectives are needed to meet these challenges. This includes not only gender diversity but also diversity in class, race, national origin and religion and other aspects of cultural experience. Let me close with a final quotation, again adapted from Sheila Widnall's remarks in 2000:

"What I want to see are [university] classrooms full of bright, young, enthusiastic students, male and female in roughly equal proportions, who are excited about the challenge of [addressing the] problems facing our society. These women want it all. They want full lives. They want important work. They want satisfying careers. And in demanding this, they will make it better for their male colleagues as well. They will connect with the important issues facing our society. Then I will know that [academic institutions have] a future contribution to make to our society" [5].

Acknowledgments: It would be impossible for me to list the many women and men who supported me as mentors and colleagues over my career. I am deeply indebted to all of them and am honored to count many of them as my personal friends. I would like to dedicate this work to my mother, Barbara Gordon Hering (1923-2016), a pioneer in her career as an attorney. She was an inspiration for me, my two brothers, her two granddaughters and my father, her husband for nearly 60 years.

Author contributions: Conceived of and written by JGH.

Funding sources: This work was not supported by any funding sources external to Eawag.

Article note: A special collection of invited papers by recipients of the IUPAC Distinguished Women in Chemistry and Chemical Engineering Awards.

\section{References}

[1] B. Kellerman, D. L. Rhode, eds. Women and Leadership: The State of Play and Strategies for Change, pp. 501, Jossey-Bass, San Francisco (2007).

[2] N. O. Keohane. Thinking about Leadership, Princeton University Press, Princeton, NJ (2012).

[3] A. M. Sapienza. Managing Scientists: Leadership Strategies in Scientific Research, Wiley-Liss, Hoboken, NJ (2004).

[4] L. Tarr-Whelan. Women Lead the Way: Your Guide to Stepping Up to Leadership and Changing the World, Berrett-Koehler Publishers, San Francisco (2009).

[5] S. E. Widnall. Digits of Pi: Barriers and Enablers for Women in Engineering. National Academy of Engineering; https://speakola.com/ideas/sheila-e-widnall-national-academy-of-engineering-2000 (2000).

[6] Eawag, Annual Report 2006. Dübendorf: Swiss Federal Institute of Aquatic Science and Technology; pp. 68 (2007). https://www.eawag.ch/fileadmin/Domain1/About/Portraet/Jahresbericht/Reports/eawag_annualreport_06.pdf

[7] Eawag, Annual Report 2017. Dübendorf: Swiss Federal Institute of Aquatic Science and Technology; pp. 79 (2018). https://www.eawag.ch/fileadmin/Domain1/About/Portraet/Jahresbericht/Reports/17e.pdf. 
[8] L. E. Ford. Politics Groups and Identities 4, 499 (2016).

[9] B. Read, B. M. Kehm. Stud. High. Educ. 41, 815 (2016).

[10] A. Bryant. Quick and Nimble, St. Martin's Press, New York (2014).

[11] R. B. Cialdini. Influence: The Psychology of Persuasion, Collins Business, New York (2007).

[12] J. Collins. Harvard Bus. Rev. January, 66 (2001).

[13] T. Harford. Adapt: Why Success Always Starts With Failure, Little, Brown, London (2011).

[14] G. McKeown. Essentialism: The Disciplined Pursuit of Less, Crown Business, New York (2014).

[15] D. H. Pink. Drive, Riverhead Books, New York (2009).

[16] R. I. Sutton. Good Boss, Bad Boss, Hachette Book Group, New York (2010).

[17] C. Rogers. Women. Stud. Int. Forum 61, 115 (2017).

[18] Eawag Partnership Programme for Developing Countries, https://www.eawag.ch/en/teaching/academic-education/epp/ (accessed May 28, 2018).

[19] C. Lüthi. Sandec News 19, 26 (2018).

[20] Eawag's Research Environment: A Guide for New and Prospective Tenure-Track and Tenured Researchers. Dübendorf: Eawag; pp. 12. https://www.eawag.ch/fileadmin/user_upload/Eawags_research_environment_PrinterVers_18092015.pdf.

[21] M. Heffernan. Beyond Measure: The Big Impact of Small Changes, Simon \& Schuster/TED, New York (2015).

[22] A. Rezvani, A. Chang, A. Wiewiora, N. M. Ashkanasy, P. J. Jordan, R. Zolin. Int. J. Proj. Manage. 34, 1112 (2016).

[23] Equal opportunities, https://www.eawag.ch/en/aboutus/working/equalopportunities/ (accessed May 24, 2018).

[24] R. I. L. Eggen, J. Hollender, A. Joss, M. Schärer, C. Stamm. Environ. Sci. Technol. 48, 7683 (2014) DOI: 10.1021/es500907n.

[25] Welcome at Vuna Ltd., an Eawag spin-off, http://www.vuna.ch/index_en.html (accessed May 28, 2018).

[26] N. Obers. High. Educ. Res. Dev. 34, 1220 (2015).

[27] I. Bohnet. What Works: Gender Equality by Design, Belknap Press, Cambridge, MA (2016).

[28] S. Sandberg. Lean In: Women, Work and the Will to Lead, Alfred A. Knopf, New York, (2013).

[29] ETH Women Professors Forum, https://eth-wpf.ch/ (accessed May 18, 2018).

[30] Advancement of Women, http://www.nccr-must.ch/advancement_of_women.html (accessed May 28, 2018).

[31] Yale Women Faculty Forum, https://wff.yale.edu/ (accessed May 18, 2018).

[32] S. A. Hewlett, M. Marshall, L. Sherbin. Harvard Bus. Rev. October, 131 (2011).

[33] F. Dominici, L. P. Fried, S. L. Zeger. So Few Women Leaders. Academe, pp. 3 (2009), https://www.aaup.org/article/so-fewwomen-leaders.WuiEgtVL-M8.

[34] M. Bismark, J. Morris, L. Thomas, E. Loh, G. Phelps, H. Dickinson. BMJ Open 5, e009384 (2015).

[35] P. Burkinshaw, K. White. Administrative Sciences 7 (3), 30 (2017).

[36] J. Bystydzienski, N. Thomas, S. Howe, A. Desai. Stud. High. Educ. 42, 2301 (2017).

[37] D. A. Aga, N. Noorderhaven, B. Vallejo. Int. J. Proj. Manag. 34, 806 (2016).

[38] V. Holton, F. E. Dent. Gender in Management 31, 542 (2016).

[39] DG Research. Women in Science and Technology - the business perspective. Brussels: European Commission; pp. 144 (2006). http://www.genderportal.eu/sites/default/files/resource_pool/KINA22065ENC_002.pdf.

[40] S. J. Aiston, J. S. Jung. Gender and Education 27, 205 (2015) DOI: 10.1080/09540253.2015.1024617.

[41] L. M. Rustad, M. E. Ryste, eds. Talent at Stake. Changing the Culture of Research - Gender-sensitive Leadership, pp. 68, Norwegian Ministry of Education and Research, Oslo (2010).

[42] NCWGE. Women and STEM: Preparing for a Technology-Driven Economy, in Title IX at 45: Advancing Opportunity through Equality in Education. National Coalition for Women and Girls in Education: Washington, DC. p. 14 (2017).

[43] L. Morley. High. Educ. Res. Dev. 33, 114 (2014).

[44] N. Jarboe. WomenCount: Leaders in Higher Education 2016. WomenCount; pp. 47 (2016) https://women-count.org/portfolio/womencount-leaders-in-higher-education-2016/.

[45] Effective Practices for Faculty Recruitment and Retention, https:/www.aps.org/programs/women/reports/cswppractices/ faculty.cfm (accessed May 15, 2018).

[46] L. Wang, A. Widener. Chem. Eng. News 95, 28 (2017).

[47] National Academies of Sciences Engineering Medicine. Sexual Harassment of Women: Climate, Culture, and Consequences in Academic Sciences, Engineering, and Medicine, The National Academies Press, Washington, DC (2018). 